\title{
The Evaluation of Serum Il-6 Changes as Proliferative Cytokines in Patients With Nasopharyngeal Carcinoma Before and After the Ionizing Radiotherapy
}

\author{
Abdul kadir ${ }^{1}$, Kurnia Retnowati ${ }^{1}$, M. Amsyar Akil ${ }^{1}$, \& Andi Nilawati Usman ${ }^{2}$ \\ ${ }^{1}$ Department of ear, Nose, Throat, Head-Neck Surgery, Medical Faculty, Hasanuddin University, Indonesia \\ ${ }^{2}$ Halal Center, Public Health Faculty, Hasanuddin University, Indonesia \\ Correspondence: Andi Nilawati Usman, Halal Center, Public Health Faculty, Hasanuddin University, Indonesia
}

Received: May 19, 2018 Accepted: June 24, 2018 Online Published: July 11, 2018

doi:10.5539/gjhs.v10n8p55 URL: https://doi.org/10.5539/gjhs.v10n8p55

\begin{abstract}
Background: Nasopharyngeal carcinoma is a squamous cell malignancy derived from the nasopharyngeal epithelial layer. This study aimed to calculate the IL-6 levels in patients with nasopharyngeal carcinoma before and after radiotherapy, in the week I and week 3 during the radiotherapy, and 2 weeks after the radiotherapy.

Methods: The study was conducted in a prospective cohort on 16 people suffering from nasopharyngeal carcinoma and undergoing radiotherapy, i.e. 9 patients were in stage I of nasopharyngeal carcinoma and 7 people were in stage II of nasopharyngeal carcinoma. Each sample underwent the examination of IL-6 before the week I and week 3 during the radiotherapy, and 2 weeks after the radio $\neg$ therapy.

Results: The more they received the treatment with radiotherapy the greater was the decrease of serum IL-6. The percentages of the decrease of the levels of serum IL-6 was greater in those receiving the 3-week duration of radiotherapy $(24.59 \%)$ compared to those who just received 1 -week duration of radiotherapy $(6.44 \%)$. The decrease of serum IL- 6 would continue, although radio-therapy had ended; 2 weeks after the radio-therapy, the percentage of serum IL- 6 decreased to $42.43 \%$ from the level of serum IL- 6 before the radio-therapy.
\end{abstract}

Conclusions: The research results indicated that there happened a significant decrease of serum IL-6 ( $<<0.05)$ after the treatment with the radio-therapy

Keywords: nasopharyngeal carcinoma, IL-6 levels, radio-therapy

\section{Introduction}

Nasopharyngeal carcinoma (NPC) is a malignancy derived from the nasopharyngeal epithelial layer and is the most common malignancy in the nasopharynx. In the Department of Otorhinolaryngology, NPC is one of the malignancies on an upper aerodigestive tract that is getting global attention because of the high mortality rate (Pieter et al., 2013).

In Indonesia, NPC is the 4th frequent carcinoma after uterine, breast and skin carcinoma, with an incidence of about 6.2 per 100,000 population. In a study conducted by Miskad (2014), in the Anatomy Pathology Laboratory of Hasanuddin University's Education Hospital, over a 10-year period, from 2005-2014, 339 cases of NPC were obtained from the total sample of 11,023 carcinomas, of which NPC was on the 9th, with breast carcinoma being the first.

It is known that Interleukin 6 is a multifunctional cytokine that plays an important role in the process of tumor development. Many studies have examined the presence of interleukin 6 in plasma. With the discovery of interleukin 6, the prognosis of a tumor becomes worse. Where IL-6 plays an important role in proliferation and inhibits binding apoptosis (IL6R $\alpha$ ) and Gp 130 (glycoprotein 130) co-receptor that activates JAK / STAT pathway (Jak kinase path) and Signal Transducer and Activator of Transcription (STATs 1 and STATs 3). And activate cell proliferation, increase angiogenesis, inhibit apoptosis, increase cancer metastasis, therapeutic resistance (Nguyen et al., 2014).

Until now the main therapy NPC is radiotherapy, but the recurrence rate after radiotherapy is still quite high, around $18 \%-45 \%$. Data showed that between $80 \%-90 \%$ NPC receiving early-stage radiotherapy may undergo 
complete remission, but the survival rate for 5 years in advanced NPCs only $10 \%-40 \%$, and if already distant metastasis have already found, $85 \%$ would die in the first year.

The main target of radiotherapy is the destruction of DNA in the cell nucleus of the carcinoma resulting in death or loss of cell ability in reproduction (proliferation). Carcinoma cell death from severe DNA damage (lethal damage) is a direct ionizing radiation effect, whereas damage to the cell's vital structure as a result of ionizing water molecules is an indirect effect.

In fact, most people are diagnosed with NPC during the symptomatic phase, but because NPC exhibits some non-specific early symptoms that are often diagnosed at an advanced stage. Less than $1 \%$ of patients are diagnosed in the asymptomatic phase and accidentally, for example, during imaging for other indications or when EBV serology is detected in health screening. The initial outbreaks are not specific such as lumps in the neck, blood-mixed snot, nasal congestion, chronic headache, cranial nerve palsy and even no symptoms in the early stages. This causes approximately $60-95 \%$ of KNF patients diagnosed at an advanced stage (III or IV) (Soewito et al., 2009). The initial diagnosis of NPC is important because the success of treatment depends on the severity of the disease.

Previous studies by Cao et al. (2011), conducted in patients with NPC found that interleukin 6 levels will increase in proportion to the increased stage of the patients and have a poor prognosis of disease. Interleukin 6 levels will decrease in patients who have undergone radiotherapy than before radiotherapy.

Thus, there is a correlation between levels of interleukin 6 in plasma and NPC, so this study is needed for early detection and is expected to diagnose NPC post radiotherapy recurrence so that the management and life expectancy can be improved. Research on the level of interleukin 6 in the blood of patients with NPC after radiotherapy has never been done in Makassar, so this study aims to calculate levels of interleukin patients NPC before undergoing radiotherapy and post radiotherapy.

\section{Materials and Methods}

\subsection{Research Time and Location}

This research was conducted at otorhinolaryngology clinic of RSUP Dr. Wahidin Sudirohusodo hospital and Hasanuddin University hospital, from August 2017 until November 2017.

\subsection{Research Design and Variables}

This research was a prospective cohort study. The variables were independent variable (radiotherapy), dependent variable (interleukin 6), and NPC.

\subsection{Population and Sample}

The population of the study was NPC patients came to otorhinolaryngology clinic RSUP Dr. Wahidin Sudirohusodo and University Hasanuddin Hospital from August 2017-November 2017. Samples are subjects from a population that meet the inclusion criteria. Total samples were 51 samples; 36 NPC patients and 15 control samples.

History of disease based on otorhinolaryngeal examination: otoscopy, rhinoscopy, anterior nasoendoscopy, pharyngoscopy, and lymph nodes of head and neck, thorax radiograph, complete blood counts, nasopharynx CT-Scan coronal slice. Patients consented to this study signed Informed Consent and underwent nasopharynx biopsy. Patients met inclusion criteria were included as samples and control were the healthy people.

Patient diagnosed as NPC were those who are histopathologically positive for nasopharyngeal carcinoma, examination of biopsy tissue by anatomical pathologists with Hematoxylin-Eosin staining, interpreted on the basis of WHO 1979 criteria. Staging method by the American Joint Committee on Cancer (AJCC) 2010 using chest $\mathrm{X}$-ray and abdominal ultrasound.

\subsection{Protocol and Data Analysis}

Radiotherapy, a method of treating malignant diseases using ionizing rays, an optional therapy in cases of nasopharyngeal carcinoma because nasopharyngeal carcinomas are radioresponsive. For T1 and T2 doses were given 200-220 cGy per fraction, given 5 times a week to reach a total dose of 6000-7000cGy in 6 weeks. For T3-T4 a total radiation dose of $7000-7500 \mathrm{cGy}$.

Interleukin 6 level as proinflammation marker examination was done in Hasanuddin University Hospital, Biomoleculer Laboratory using Enzyme-linked Immunosorbent Assay (ELISA). Reagent was LifeSpan BioSciences, Inc., USA, procedures of examination based on its instruction. 
Data presented in table with mean, standar deviation and frequency. Categorical data analyzed using Chi square test, all numerical data was all numerical data were analyzed data distribution using shapiro wilk test. Normally distributed data were tested with parametric statistical (Independent sample T-test) tests and non-distributed data were tested by nonparametric tests (Mann-whitney, Kruskall Wallis, Wlicoxon). Significance level was 0.05 and software use was SPSS (Statistical Product and Service Solution).

\section{Results}

The sample characteristics data showed that the age between patients with NPC and healthy control differed significantly, the sample characteristics data showed that the age between patients with NPC and healthy control differed significantly but no significant gender and ethnic differences between the two groups (Table 1).

Table 1. Characteristic of samples

\begin{tabular}{lllll}
\hline \multirow{2}{*}{$\begin{array}{l}\text { Characteristic } \\
\text { Age (year) }\end{array}$} & Mean \pm SD & $\begin{array}{l}\text { NPC } \\
\mathbf{n = 3 6}\end{array}$ & $\begin{array}{l}\text { Control } \\
\mathbf{n = 1 5}\end{array}$ & \multirow{2}{*}{ P-value } \\
\cline { 2 - 4 } Gender & Male & $43,4 \pm 6,0$ & $32,7 \pm 5,1$ & $<0,001^{*}$ \\
\hline \multirow{2}{*}{ Ethnicity } & Female & $21(58.33)$ & 9 & $1,000^{* *}$ \\
& Buginese & $15(41.67)$ & 6 & $0,807^{* *}$ \\
\hline
\end{tabular}

*Independent sample $\mathrm{t}$ test; ${ }^{* *}$ Chi square test.

Comparison of serum IL-6 levels between NPC and control showed that serum IL-6 levels in patients with nasopharyngeal carcinoma were much higher (144,188 x 104) than control $(28,835 \times 104)$; serum IL-6 levels of patients with nasopharyngeal carcinoma are about $5 \times$ higher than controls (Table 2 ).

Table 2. Comparison of IL-6 level serum between nasopharyngeal carsinoma with control

\begin{tabular}{llll}
\hline \multirow{2}{*}{ Group } & \multicolumn{2}{l}{ Level of IL-6 serum (10 $\mathbf{p g} / \mathbf{m L})$} & \multicolumn{2}{c}{ P-value* $^{*}$} \\
\cline { 2 - 3 } & Min/Max (Median) & Mean \pm SD & $<0,0001$ \\
\hline Carsinoma Nasopharngeal $(\mathrm{n}=36)$ & $49,26 / 191,43(144,188)$ & $122,016 \pm 49,648$ & \\
Control $(\mathrm{n}=15)$ & $22,19 / 33,99(28,835)$ & $28,713 \pm 3,188$ & \\
\hline
\end{tabular}

*Mann-Whitney.

Table 3. Comparison of IL-6 level serum between nasopharyngeal carsinoma based on stadium of cancer

\begin{tabular}{llll}
\hline \multirow{2}{*}{ Nasopharyngeal Carsinoma Stadium } & \multicolumn{3}{l}{ Kadar IL-6 serum (x10 pg/mL) } \\
\cline { 2 - 4 } & Min/Max (Median) & Mean \pm SD & p* \\
\hline Stadium $1(\mathrm{n}=9)$ & $49,26 / 57,82(54,769)$ & $53,804 \pm 2,847^{\mathrm{a}}$ & \\
Stadium $2(\mathrm{n}=7)$ & $90,35 / 97,62(96,124)$ & $95,595 \pm 2,486^{\mathrm{b}}$ & $<0,0001$ \\
Stadium $3(\mathrm{n}=13)$ & $133,27 / 155,68(148,838)$ & $148,721 \pm 6,161^{\mathrm{c}}$ & \\
Stadium $4(\mathrm{n}=7)$ & $165,28 / 191,43(189,568)$ & $186,542 \pm 9,451^{\mathrm{d}}$ \\
\hline
\end{tabular}

*Kruskall-Wallis. 
Table 4. Decreasing of IL-6 serum level after radiotherapy

\begin{tabular}{llll}
\hline \multirow{2}{*}{ Radiotherapy (RT) } & \multicolumn{2}{c}{ Level of IL-6 serum $(\mathbf{x 1 0} \mathbf{p g} / \mathbf{m L})$} & \multirow{2}{*}{$\mathbf{p}^{*}$} \\
\cline { 2 - 4 } & Becreasing(\%) & $<0,001$ \\
1 week duration of RT & $67,407 \pm 20,677$ & $4,680(6,44 \%)^{\mathrm{a}}$ & $<0,001$ \\
3 week duration of RT & $53,879 \pm 15,117$ & $18,208(24,59 \%)^{\mathrm{b}}$ & $<0,001$ \\
2-Minggu Post RT & $40,728 \pm 8,036$ & $31,359(42,43 \%)^{\mathrm{c}}$ & \\
\hline
\end{tabular}

*Wilcoxon;**Mann-Whitney.

Comparison of serum IL-6 levels based on the NPC stage showed that serum IL-6 levels were associated with the NPC stages; the higher the stage, the higher serum IL-6 levels. Serum IL-6 levels were higher in stage 4 and lowest in stage $1(189,568$ vs 148,838 vs 96,124 vs 54,769$)$ (Table 3 ).

Changes in serum IL-6 levels after 1-week during radiotherapy and 3-week during radiotherapy showed a significant decrease in serum IL-6 $(\mathrm{p}<0.05)$ after obtaining radiotherapy measures. The more radiotherapy action, the greater the serum IL-6 decrease. The percentage decrease in serum IL-6 levels was greater in those who received 3-week duration of radiotherapy $(24.59 \%)$ than the newly acquired 1-week duration of radiotherapy (6.44\%). Serum IL-6 decrease persists, although radiotherapy measures are over; after 2 weeks post-radiotherapy the percentage of serum IL-6 decrease to $42.43 \%$ of serum IL-6 levels before radiotherapy (Table 4 ).

\section{Discussion}

This study shows the interleukin level of NPC patients before and after radiotherapy were higher than 1-week and 3 -week during radiotherapy and $2^{\text {nd }}$-week post radiotherapy cycle. In this study, majority of patients with NPC were at the age of 40 years, which accounted for 36 samples, this can be caused by the older the individual the more possibility exposed by free radicals so that oxidative stress in individuals is higher, thus increasing the risk of exposure carcinoma disease.

The majority of the samples in this study were male (21) and female (15). The characteristics of sex and ethnic groups can be considered homogeneous between the two groups ( $p>0.05)$. This may be caused by several environmental factors, one of which, men tend to work more often outside, thus more exposed to wood dust and smoke which is a predisposing factor of NPC occurrence. Also, life habits such as smoking or alcohol are higher among men than women.

In this study, there was a statistically significant relationship $(\mathrm{p}<0.05)$ between levels of interleukin 6 of NPC with an average value of $122.016 \pm 49.648 \mathrm{pg} / \mathrm{mL}$, higher than in the control group, obtained an average score of 28.713 $\pm 3.188 \mathrm{pg} / \mathrm{mL}$. In accordance with Nguyen et al. (2014), Interleukin 6 is associated with tumorigenesis by increasing proliferation, migration and tumor cell invasion, enhancing angiogenesis, inhibiting apoptosis via STATs pathways.

Serum IL-6 levels were associated with stage of nasopharyngeal carcinoma; the higher the stage, the higher serum IL-6 levels. Serum IL-6 levels were higher in stage 4 and lowest in stage 1 (189.568 vs 148.838 vs 96.124 vs 54.769). This is in accordance with a study conducted by Cao et al. (2011), which was performed on nasopharyngeal patients, in which interleukin 6 levels will increase in proportion to the increase stage of patients with NPC. Theoretically, interleukin 6 increases in accordance of increased regulation of MMP-2 expression, and MMP-9 in carcinoma cells through LMP1, in which the production of IL-6 which plays role in spurring ICAM as a facilitator of metastasis and angiogenesis, proliferation, migration and tumor cell invasion through NFK $\beta$ pathway.

In this study, IL-6 serum was not affected by NPC cell type. Based on statistical test results using Mann-Whitney test showed that levels of interleukin 6 were not influenced by histopathologic picture of WHO Type II and III NPC patients ( $p>0.05)$. In accordance with Poh et al. (2012), that stated that NPC with type II and III WHO is strongly associated with Epstein-Barr virus infection.

Interleukin 6 levels are associated with radiotherapy, which was proved by a significant decrease in serum IL-6 (p $<0.05$ ) after obtaining radiotherapy measures. The more radiotherapy, the greater the serum IL- 6 decrease. The percentage of decrease in serum IL-6 levels was greater in those who received radiotherapy measures at week 3 of radiotherapy $(24.59 \%)$ than those receiving radiotherapy at week 1 radiotherapy $(6.44 \%)$. Serum IL-6 decrease persists, although the RT action is over; after 2 weeks post RT percentage decrease serum IL- 6 to $42.43 \%$ from serum IL-6 level before RT. This is according to research conducted by Cao et al. (2011), levels of interleukin 6 will decrease in patients after radiotherapy than before radiotherapy. Study by Jin et al. (2017), in patients with 
NPC, thelevels of IL-6, IL-5, IL-1 $\beta$ will decrease after therapy. According to Barker et al. (2015), radiotherapy affects tumor microenviroment (TME) including endothelial damage resulting in increased ICAM and VCAM, leukocyte adhesion. The target of radiotherapy is TGF $\beta, N F-k \beta$. Where activated NF-k $\beta$ may increase IL-6.

It is well known that carcinoma cells are exacerbated by chronic inflammation. The major role in this linkage is the cytokines and chemokines produced by carcinoma cells and immune cells that are activated. Interleukin-6 (IL-6), is a pleiotropic cytokine with various biological activities secreted by different cell types including macrophages, B and T lymphocytes, fibroblasts, endothelial cells, keratinocytes and carcinoma cells (Jinno et al., 2015).

A number of studies support the fact that some biomarkers are released in the cell carcinoma of the head and neck. In particular, IL-6 and IL-8 are important factors in predicting cell differentiation and tumor cell growth. Increases in renal cell carcinoma, oral cavity carcinoma and lymphoma have been reported. In one study increased IL-1 $\alpha$, IL-6, IL-8, vascular endothelial growth factor A (VEGF-a) and TNF- $\alpha$ can predict the development of SCC of the tongue from high-risk neoplasms, and may as potential biomarkers for carcinoma screening (Lotfi et al., 2015).

In this study there are some limitations, which is the follow up examination of interleukin 62 weeks after radiotherapy should be done in months 1.3 , and 6 so we can know the time of increase and duration of decrease in levels of IL-6 which later can assess the improvement therapy or assess tumor recurrence. Another limitation is cancer recurrence and its correlation with IL-6 has not be evaluated.

\section{Conclusion}

The investigators concluded that Interleukin 6 was higher in patients with nasopharyngeal carcinoma prior to radiotherapy compared with patients with nasopharyngeal carcinoma after radiotherapy. Interleukin 6 is higher in advanced stage nasopharyngeal carcinoma (stage III and IV). Levels of interleukin 6 patients nasopharyngeal carcinoma before radiotherapy is higher than week 1, week 3 during radiotherapy and week 2 post radiotherapy cycle. Researchers recommend that examination of levels of interleukin 6 in patients with nasopharyngeal carcinoma may be considered as diagnostic methods, remedial therapy and additional prognostics. A follow-up study is needed to check the levels of interleukin in 6 patients with completed radiophysiotherapy and follow-up of controls at 1,3 , and 6 months after radiotherapy.

\section{Acknowledgements}

We thank all the laboratory staff who have helped.

\section{Competing Interests Statement}

The authors declare no conflict of interest.

\section{References}

Barker, H. E., Paget, J. T., Khan, A. A., \& Harrington, K. J. (2015). The tumour microenvironment after radiotherapy: mechanisms of resistance and recurrence. Nature reviews Cancer, 15(7), 409. https://doi.org/10.1038/nrc3958

Cao, S. M., Simons, M. J., \& Qian, C. N. (2011). The prevalence and prevention of nasopharyngeal carcinoma in China. Chinese journal of cancer, 30(2), 114. https://doi.org/10.5732/cjc.010.10377

Jin, Y. B., Zhang, G. Y., Lin, K. R., Chen, X. P., Cui, J. H., Wang, Y. J., \& Luo, W. (2017). Changes of plasma cytokines and chemokines expression level in nasopharyngeal carcinoma patients after treatment with definitive intensity-modulated radiotherapy (IMRT). PloS one, 12(2), e0172264. https://doi.org/10.1371/journal.pone.0172264

JiNNO, T., KAwAnO, S., Maruse, Y., MATSUbARA, R. Y. O. T. A., Goto, Y., Sakamoto, T., ... \& Toyoshima, T. (2015). Increased expression of interleukin-6 predicts poor response to chemoradiotherapy and unfavorable prognosis in oral squamous cell carcinoma. Oncology reports, 33(5), 2161-2168. https://doi.org/10.3892/or.2015.3838

Lotfi, A., Shahidi, N., Bayazian, G., AbdollahiFakhim, S., Estakhri, R., Esfahani, A., \& Notash, R. (2015). Serum level of interleukin-6 in patients with oral tongue squamous cell carcinoma. Iranian journal of otorhinolaryngology, 27(80), 207.

Miskad U. A. (2014). Identify and Analyze Molecular Markers in the Progression and Metastasis of Colorectal Cancer.

Nguyen, D. P., Li, J., \& Tewari, A. K. (2014). Inflammation and prostate cancer: the role of interleukin 6 (IL - 6). BJU international, 113(6), 986-992. https://doi.org/10.1111/bju.12452 
Pieter N. A. I. dkk. (2013). Profile of IgA (VCA-p18 + EBNA1) and Viral Load DNA EBV As Family Risk Factors Patients with Nasopharyngeal Carcinoma with Positive EBV. Dissertation of Doctoral Program. Makassar: Post Graduate of Hasanuddin University.

Poh, Y. W., Gan, S. Y., \& Tan, E. L. (2012). Effects of IL-6, IL-10 and TGF-beta on the expression of survivin and apoptosis in nasopharyngeal carcinoma TWh01 cells. Exp Oncol, 34, 85-89.

Soewito, M. dkk. (2009). IgA Antibodies Response (VCA-p18 + EBNA 1) Against EPSTEIN-BARR VIRUS (EBV) In Family Patients with Nasopharyngeal Carcinoma in Makassar. (Thesis of Graduate Program Makassar: Post Graduate of Hasanuddin University).

\section{Copyrights}

Copyright for this article is retained by the author(s), with first publication rights granted to the journal.

This is an open-access article distributed under the terms and conditions of the Creative Commons Attribution license (http://creativecommons.org/licenses/by/4.0/). 